\title{
Um enredamento para o novo falso: um processo em nós
}

\author{
Davi Junqueira Marin' \\ https://orcid.org/ 0000-0001-6231-1136 \\ I - PUC-SP \\ São Paulo (SP), Brasil.
}

NOBRE DOS SANTOS, K. Em busca da credibilidade perdida: a rede de investigação jornalística na era das fake news. Belo Horizonte, Letramento, 2018. 164 p.

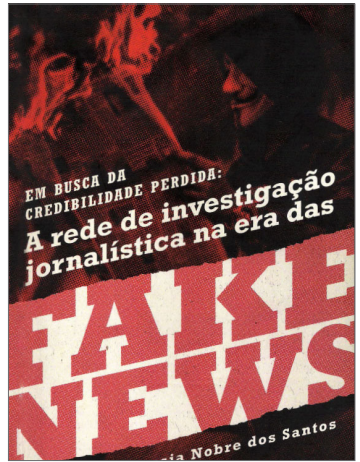

Resumo: O jornalismo está em crise e sob o risco de extinção em tempos de pós-verdade e de fenômenos fake news. Kassia Nobre sugere quatro etapas para um processo de criação e checagem da reportagem que deve garantir e atestar a veracidade da informação diante de seus leitores na retomada da suposta ou temida quebra da relação de confiança nas mídias, ou entre alguns veículos e seus leitores ou telespectadores, suas audiências. Além do corpus e objetos estudados, o percurso do texto é, em si mesmo, a exemplificação da teoria apresentada e a vivificação de sua própria sugestão: seus quatro nós estão presentes na temática do percurso do texto, encabeçando e encadeando os títulos dos capítulos. A presente resenha enfatiza a atualidade e relevância do tema, bem como a simetria do texto em relação à teoria estudada e à própria teoria inédita apresentada.

Palavras-chave: crise no jornalismo; revista Piauí; agência Lupa; processo criativo.

Abstract: An entanglement to the new fake: a knot process [Searching for the lost credibility: investigative journalism network in the fake news era] - Journalism is in a crisis and at risk of extinction in times of post-truth and fake news phenomena. Kassia Nobre suggests four steps for the creative process of reporting and checking the news that should guarantee and attest the information's veracity before its readers, resuming the supposed or feared breach of trust in the media, or between some vehicles and their readers or viewers, their audiences. In addition to the corpus and objects studied, the text's path is, in itself, an example of the theory presented and the vivification of its own suggestion. Its four nodes are presented within 
the theme of the text's path, heading, and chaining the chapter titles. The present review emphasizes the topicality and relevance of the theme, as well as the symmetry of the text in relation to the theory studied and the unpublished theory itself.

Keywords: crisis in journalism; Piauí magazine; Lupa agency; creative process.

Segundo Kassia, um bom percurso para trazer de volta a credibilidade perdida do jornalismo, crença evaporada das reportagens e dos trabalhos dos jornalistas em geral, estaria na evolução das qualidades dessas mesmas reportagens, dos estilos jornalísticos que poderiam se fazer valer, a exemplo da própria revista, de artifícios migrados de outras linguagens, mesclando as técnicas jornalísticas a estilos ou técnicas narrativas provindas da literatura e do cinema, por exemplo, na intenção de dar conta da diversidade e pluralidade de estilos de linguagem que pululam pelas atuais redes eletrônicas. Assim, uma reportagem bem acabada, bem escrita, que mais tempo gasta em sua elaboração, concepção e mesmo apuração ou checagem das informações seriam as principais armas na guerra contra as fake news. Segundo a autora, a simples retomada de um jornalismo mais tradicional, autoral, que traga para os leitores consumidores de notícias e reportagens melhor contextualização da informação através de recursos narrativos mais sofisticados, conseguiria liderar a atenção desses leitores para uma retomada de credibilidade da profissão, do meio como um todo e dos produtos jornalísticos enquanto construção ou espelhamento da verdade de mundo e de informação sobre o real.

Depois de abrir o texto retomando um breve histórico do jornalismo com ênfase nessas iniciativas ao longo de sua história (a ideia de notícias fake não é tão new assim), a autora traz exemplos dos movimentos do New Journalism norte americano que ilustram o percurso do raciocínio da autora em sua intenção, na busca de resolver a questão da credibilidade atual por meio de uma alteração sutil no processo criativo gerador do fato, da notícia e de registros, com suas tendências particulares. Retomando os grandes movimentos do jornalismo desde a revolução da prensa de Gutenberg até a invenção da imprensa, a autora nos lembra dos três jornalismos até a metade do século XX; ela sugere que o que quer que tenha sido um problema antes, ou em outros tempos ou momentos do jornalismo, hoje talvez seja novamente sua pedra de toque, seu ponto chave, seu fundamento de base, sua sobrevivência ou retomada em meio às crises diante dos fenômenos da pós-verdade e das fake news.

Contextualizando a espacialidade e a temporalidade de seu texto através do recorte do que autores passaram então a chamar de pós-verdade, a autora define o contexto da pesquisa transformada em livro a partir desse mesmo momento presente, o tempo da pós-verdade que traz seu fruto, as fake news.

A autora define a análise de seu objeto na relação da revista Piauí com a agência Lupa a partir da ligação desses dois elementos com os quatro pontos nodais, os quatro nós delineados por ela mesma - espécies de pontos chave para a construção de um caminho 
mais sustentável e consistente para o jornalismo não apenas brasileiro, mas para todo o campo ou meio jornalístico em si - , definindo em seu desenho a sugestão de um processo criativo para o jornalismo, conceitualmente, como sendo então essas quatro etapas ou nós de investigação:

1. o tempo da investigação;

2. a narratividade;

3. a transparência; e

4. a correção do erro.

Esses quatro nós perpassam tanto a revista - objeto da análise - quanto a agência de checagem, também parte integrante do objeto, que na verdade são dois, buscando resgatar, segundo a autora, a credibilidade dos meios de comunicação tradicionais como um todo, especialmente para veículos com amplo cruzamento com a web-como é o caso da própria revista e da agencia Lupa - que fornecem material e produtos jornalísticos para meios e veículos (como a Folha de S. Paulo, o portal UOL, entre outros), e que surgem, por natureza e em função do novo meio, na checagem das fake news. Assim, a revista, que nasce ainda na galáxia tipográfica, hospeda em seu site uma agência de checagem que trabalha para assegurar a verdade no meio eletrônico. Ambos, um com um pé na origem tipográfica e outro eletrônico, estabelecem boa simbiose entre esses quatro nós, o que, segundo a autora, seriam espécies de pontos de ancoragem para a credibilidade jornalística que busca sobreviver ou se realinhar em seus meios e nas águas turvas e turbulentas da rede nesses tempos de fake news. Sintetizando os quatro nós, está o movimento sincronizado do bom uso cuidadoso e paciencioso dos tempos da confecção dos textos intimamente associados a um enriquecimento narrativo sempre aberto ou passível de se colocar às provas e checagens de terceiros, como as agências de fact-checking que a autora ilustra com inúmeros exemplos e dados relevantes.

Percursos recentes ao longo do livro, em notas de rodapé, página a página, comprovam, atestam e exibem o alinhamento de seu próprio trabalho à proposta enquanto método não apenas para o meio corporativo, mas para si mesma. Nobre dos Santos enriquece a tessitura de seu próprio texto com aspectos históricos interessantes bastante relevantes para que os leitores consigam compor mentalmente o panorama da cena completa desse percurso que desemboca em nossos dias, ao mesmo tempo em que amarra a escritura da análise aos dados sempre passíveis de serem checados em bibliografia exposta da mesma maneira através das referências e das citações e pelos endereços da web indicados também nas anotações página a página em rodapés e entre os parênteses no corpo do texto. Assim, o quarto nó é sua própria consideração final que, a partir de uma síntese de todo o trabalho, permite a sugestão da correção do erro, por meio do uso e da combinação dos outros nós (quatro nós, ou nós, ou nós quatro, então, ganham nova subjetividade e alçam novo voo na semiótica possível de ser estabelecida pelo texto: 
esses nós podem ser nós mesmos, enquanto profissionais atuantes no meio específico ou enquanto leitores ou audiência atenta). O livro exemplifica, vivifica sua própria teoria e seu próprio objeto de análise e se transforma, ao longo de todo o percurso, em solução para seu problema de pesquisa.

De leitura tranquila, a qualidade da produção gráfica e da diagramação também ajudam. Excelente para estudantes ou profissionais de comunicação, de semiótica ou especialmente da área jornalística, o livro de Nobre dos Santos já nasce com uma aura de clássico, essencial para nosso momento histórico e enquanto forma de registro desse processo criativo que a autora enfatiza ao longo de sua explanação, transformando-se, mais uma vez, em objeto de espelhamento de sua própria pesquisa. A obra é, em si, registro importante para o processo em que se insere o contexto atual das fake news, com todas as nuances de suas feituras. O livro de Kassia é, então, registro de toda essa gama de complexidades de que a autora mesmo fala e trabalha junto com outros autores acerca dessa mesma temática da complexidade. A autora caminha, o tempo todo, de mãos dadas com Morin e Salles, e seu texto registra e se torna também o registro, em sua complexidade, de todos esses movimentos criativos, movimentos da verdade e de comunicação registrados em rede e pelas redes.

Não apenas em função do conteúdo disciplinar para as áreas de comunicação, ciências sociais e humanidades, a obra de Nobre dos Santos é multi e transdisciplinar, especialmente quando fazemos uma análise estrutural de seu texto, de sua escritura, de seu percurso teórico através de suas linhas de raciocínio. Seu texto é simetricamente tão bem resolvido que parece até mesmo mais coerente uma avaliação ou resenha sob um olhar ou percepção semiótica. Para um observador da semiose do texto como um todo, o texto em si parece sugerir uma representação gráfica de si mesmo, e se projeta sobre sua leitura como uma imagem, com geometria e matemáticas próprias. São cinco capítulos que são sintetizados em sua sexta parte, a consideração final, e que trabalha dois objetos inseridos em nós, quatro pontos chave, ou quatro nós, como vimos. A sugestão de uma relação dialética interna ao objeto é evidente e nítida: a geração da verdade deve ser autocorretiva, autocrítica. A verdade (narrada, reportada ou construída do zero) deve permitir-se a correção, a checagem, a autocrítica. Assim, de acordo com o objeto e sua análise, a geração da notícia deve caminhar lado a lado com sua verificação, desde sua origem, como é o caso da revista que hospeda sua própria correção. Os quatro nós concluem a direção desse percurso criativo de reportagem da verdade, percurso que deve sempre ser enriquecido com paciência em sua busca e confecção, com apreço e capricho linguístico e estilístico sem cair na fantasia e no delírio, mantendo sempre a transparência a partir de um enfoque narrativo que permita a ampliação da percepção e da visualização da cena como um todo pelos leitores consumidores da informação jornalística. O enredo, o enredamento, como traz Paul Ricouer (2016), aqui ganha uma nova conotação e sugere não a ficção, a mentira, mas o percurso para a verdade. A partir daqui, enredamento está 
virado contra o próprio falso. Espécie de feitiço contra o feiticeiro, o enredamento do texto deve ser um processo presente em nós, nós da criação da informação, nós do enredamento da notícia e da reportagem, nós de um processo criativo aberto que se registram também abertamente em rede. A correção do erro deve, então, ser uma espécie de constante que caminhe na paralela dessa construção, passo a passo, momento a momento: a cereja do bolo é seu atestado de veracidade.

Davi Junqueira Marin é doutorando na PUC-SP.

marin.davi@yahoo.com.br

\section{Referências}

MORIN, E. O método 4. As idéias. Habitat, vida, costumes, organização. Porto Alegre: Editora Sulina, 2002. 320 p.

SALLES, C. A. Redes da Criação. Construção da obra de arte. Vinhedo: Editora Horizonte, 2016. 176 p. SANTOS, K. N. Em busca da credibilidade perdida: a rede de investigação jornalística na era das fake news. Belo Horizonte, Letramento, 2018. 164 p.

RICOEUR, P. Tempo e Narrativa 2 - a configuração do tempo na narrativa de ficção. São Paulo: WWF Martins Fontes, 2016. 280 p. 